\title{
Quantitative Assessment of Renal Perfusion and Oxygenation by Invasive Probes: Basic Concepts
}

\author{
Kathleen Cantow, Roger G. Evans, Dirk Grosenick, Thomas Gladytz, \\ Thoralf Niendorf, Bert Flemming, and Erdmann Seeliger
}

\begin{abstract}
Renal tissue hypoperfusion and hypoxia are early key elements in the pathophysiology of acute kidney injury of various origins, and may also promote progression from acute injury to chronic kidney disease. Here we describe basic principles of methodology to quantify renal hemodynamics and tissue oxygenation by means of invasive probes in experimental animals. Advantages and disadvantages of the various methods are discussed in the context of the heterogeneity of renal tissue perfusion and oxygenation.

This chapter is based upon work from the COST Action PARENCHIMA, a community-driven network funded by the European Cooperation in Science and Technology (COST) program of the European Union, which aims to improve the reproducibility and standardization of renal MRI biomarkers. This introduction chapter is complemented by a separate chapter describing the experimental procedure and data analysis.
\end{abstract}

Key words Renal hemodynamics and oxygenation, In vivo methods, Quantitative invasive probes

1 Introduction

Kidney diseases are a global health burden with steadily increasing prevalence and incidence [1-5]. Animal studies have provided evidence that acute kidney injury (AKI) of various origins shares a common link in the pathophysiological chain of events, ultimately leading to AKI, as well as to progression from AKI to chronic kidney disease $(\mathrm{CKD})$ : imbalance between renal oxygen delivery and oxygen demand [3,6-13]. Renal tissue hypoperfusion and hypoxia have also been suggested to play a pivotal role in the pathophysiology of other kidney diseases including diabetic kidney disease [14-16].

The majority of the preclinical studies that generated this concept utilized a set of invasive probes to measure renal hemodynamics and oxygenation in anesthetized animals $[12,14,17-20]$. These methods have also been used (1) to study mechanisms of 
physiological control of renal hemodynamics and oxygenation and (2) the effects of various substances on this control in healthy animals, (3) to test several putative preventive or therapeutic approaches for AKI and CKD in animal models, and (4) for the purpose of calibrating functional magnetic resonance imaging (MRI) including renal blood oxygenation level-dependent MRI (BOLD-MRI) that makes use of the quantitative MR parameter $\mathrm{T}_{2}{ }^{*}$, which is a surrogate for blood oxygenation [18-28].

The invasive probes typically include (1) a perivascular flow probe for measurement of total renal blood flow, (2) laser-Doppleroptodes for assessment of local tissue perfusion, (3) Clark-type electrodes or fluorescence-quenching optodes for measurements of local tissue partial pressure of oxygen $\left(\mathrm{pO}_{2}\right)$, and $(4)$ devices for invasive measurement of arterial blood pressure. These methods are considered the gold standard for the study of renal hemodynamics and oxygenation, because the methods, with the exception of the laser-Doppler fluxmetry, provide calibrated quantitative data $[25,29,30]$. Step-by-step protocols for application of these techniques in two setups, one for stand-alone experiments in laboratories for integrative physiology, and the other for experiments within small-animal MR scanners by use of a hybrid setup, are provided in the chapter by Cantow $\mathrm{K}$ et al. "Monitoring Renal Hemodynamics and Oxygenation by Invasive Probes: Experimental Protocol".

As with all established modalities available in today's experimental and translational research, these techniques have shortcomings and methodological limitations. In particular, their invasiveness, for obvious ethical reasons, precludes their use in humans. The invasiveness is, furthermore, a considerable hurdle for implementation of these methods in long-term and longitudinal studies: although invasive probes have been used in conscious, chronically instrumented animals [22, 24, 31-37], the vast majority of studies has been performed in "terminal experiments" in anesthetized animals. This is a major limitation of all invasive techniques because the measurements are by necessity potentially confounded by the effects of anesthesia (see the chapter by Kaucsar T et al. "Preparation and Monitoring of Small Animals in Renal MRI").

The measurement of intrarenal tissue perfusion and tissue oxygenation is quite challenging, because of their vast spatial heterogeneity both among the renal layers (cortex, outer medulla, and inner medulla) and within the layers. In this chapter, the causes and the degree for this spatial variability are outlined first, before the basic principles of methodology to quantify renal hemodynamics and oxygenation by means of invasive probes in experimental animals are described together with a discussion of the pros and cons of the various methods. 
This introduction chapter is complemented by a separate chapter describing the experimental procedure, which is part of this book.

This chapter is part of the book Pohlmann A, Niendorf T (eds) (2020) Preclinical MRI of the Kidney-Methods and Protocols. Springer, New York.

\section{Heterogeneity of Intrarenal Perfusion and Oxygenation-Causes and Degree of Variability}

Intrarenal local tissue $\mathrm{pO}_{2}$ is determined by the balance between local $\mathrm{O}_{2}$ supply and local $\mathrm{O}_{2}$ consumption. Additionally, determinants of local $\mathrm{O}_{2}$ diffusion play a role. Local $\mathrm{O}_{2}$ supply depends on local blood perfusion, local vessel density, and local blood $\mathrm{pO}_{2}$ and blood $\mathrm{O}_{2}$ content. Local $\mathrm{O}_{2}$ consumption is foremost determined by local metabolic demand. Blood perfusion within the kidney is much more heterogeneous than within most other organs, due to its particular vascular architecture [8, 38-40].

From the branches of the renal artery that enter the kidney at its hilus, interlobar arteries arise, which align with the medullary-cortical axis. From interlobar arteries emerge arcuate arteries that run along the boundary between the cortex and the medulla, that is, perpendicular to the medullary-cortical axis. From the latter, interlobular arteries branch off at regular intervals at angles of about 90 degrees, so that they all enter the renal cortex. For this reason, virtually all the blood flowing into the kidney perfuses the cortex first $[8,25,38,41-43]$. The interlobular arteries are in close proximity to interlobular veins, together forming what might be called "vascular bundles" that run in parallel at regular distances from the corticomedullary boundary toward the capsule. Within the cortex, interlobular arteries branch off into afferent (preglomerular) arterioles, from which glomerular capillaries arise that, in turn, rejoin into efferent (postglomerular) arterioles. The efferent arterioles from the subcapsular and mid-cortical glomeruli branch off into networks of peritubular capillaries. The efferent arterioles of the deep cortical (juxtamedullary) glomeruli, however, branch off at about the corticomedullary boundary to form capillary-like vessels, the descending vasa recta [38-40]. These very straight and exceptionally long vessels descend toward the papilla. The descending vasa recta provide virtually all blood that perfuses the medulla. As a consequence, only $10-15 \%$ of blood that previously passes through the cortex, will reach the medulla, and the vascular density is much lower in the medulla than the cortex $[8,25,38,41-43]$. The descending vasa recta are in close proximity with the ascending vasa recta, thus forming distinct "vascular bundles" that run in parallel at regular distances through the medulla [38-40].

These particularities of the intrarenal vascular architecture have a number of salient consequences with regard to local blood 


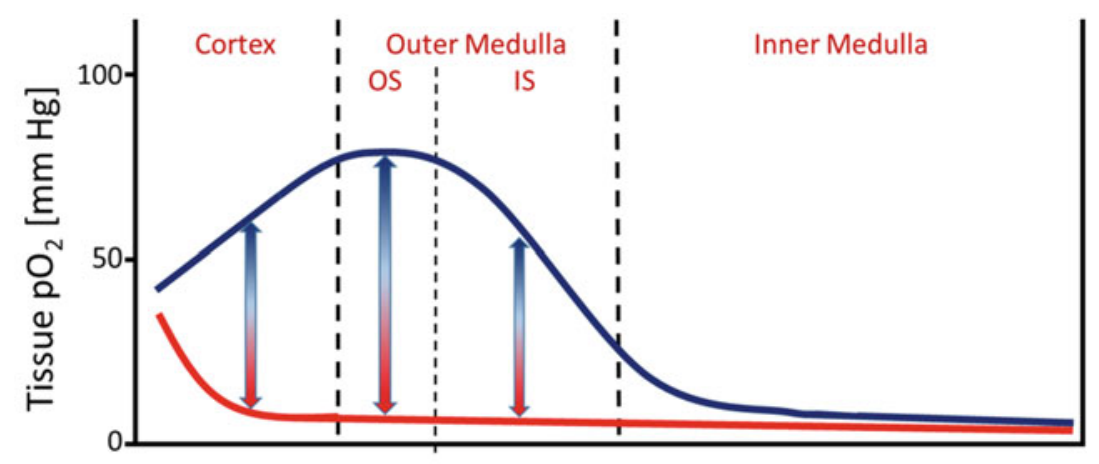

Fig. 1 Scheme depicting the range of intrarenal tissue partial pressure of oxygen $\left(\mathrm{pO}_{2}\right)$. The red curve depicts values at the greatest distance from two neighboring "vascular bundles," the blue one that directly adjacent to "vascular bundles" (for details see text); OS (outer stripe), IS (inner stripe). Original data were obtained by measurements in in anesthetized dogs and rats [43-45]

perfusion and thus the local $\mathrm{O}_{2}$ supply. First, the striking difference in the quantity of blood perfusion between the cortex and the medulla, together with the difference in their vascular densities, is one of the major reasons for the low tissue $\mathrm{pO}_{2}$ in the medulla. Second, the Fåhræus-Lindqvist effect that lowers the hematocrit and thereby the $\mathrm{O}_{2}$ content of blood in the vasa recta that supply the medulla, contributes to low medullary $\mathrm{O}_{2}$ delivery $[39,40]$. Third, diffusive shunting of $\mathrm{O}_{2}$ between the arcuate and interlobular arteries and their respective veins in the cortex as well as between the descending and ascending vasa recta in the medulla, owing to the close proximities of the respective vessels, are a further major reason behind the "physiological hypoxia" of the medulla. Thus, blood $\mathrm{pO}_{2}$ is higher in the venous vessels than in the capillaries these venous vessels drain. Fourth, due to the particular vascular architecture with distinct "vascular bundles" that comprise arterial vessels with high $\mathrm{pO}_{2}$ and venous vessels with relatively high $\mathrm{pO}_{2}$ (due mainly to the low fractional $\mathrm{O}_{2}$ extraction of the renal tissue), there are huge differences in local $\mathrm{pO}_{2}$ even within a given renal layer under physiological conditions [25, 41, 43-47]. Fifth, plasma skimming at intrarenal vessel branches results in different hematocrit and therefore $\mathrm{O}_{2}$ content of blood perfusing the daughter vessels, which also contributes to the local $\mathrm{pO}_{2}$ differences $[39,48]$.

The schematic shown in Fig. 1 depicts the range of local $\mathrm{pO}_{2}$ values as measured by invasive Clark-type electrodes in the kidneys of rats and dogs under physiological conditions in vivo [4345]. These measurements reveal that local tissue $\mathrm{pO}_{2}$ levels in the cortex vary dramatically, foremost according to the distance to the "vascular bundles" of interlobular arteries and veins: $\mathrm{pO}_{2}$ values range from $10 \mathrm{mmHg}$ at the greatest distance from two neighboring "bundles," to up to $70 \mathrm{mmHg}$ around the "bundles." In 
addition, local cortical tissue $\mathrm{pO}_{2}$ varies with the distance to the arcuate arteries located at the corticomedullary boundary. Also, the range of tissue $\mathrm{pO}_{2}$ variability in the outer medulla is huge (see Fig. 1): whereas $\mathrm{pO}_{2}$ is less than $10 \mathrm{mmHg}$ in locations at maximum distance from the "vascular bundles" of descending and ascending vasa recta, $\mathrm{pO}_{2}$ is up to $75 \mathrm{mmHg}$ in close proximity to these "bundles." In the inner medulla, tissue $\mathrm{pO}_{2}$ is rather homogenous: in general, it usually amounts to less than $15 \mathrm{mmHg}$.

The huge differences in tissue $\mathrm{pO}_{2}$ among the renal layers not only reflect the differences in $\mathrm{O}_{2}$ supply but also the different $\mathrm{O}_{2}$ consumption of the distinct sections of the tubules located in the respective renal layers. Tubular resorption relies on active transport processes, which account for about $85 \%$ of the kidney's energy expenditure and, therefore, its $\mathrm{O}_{2}$ consumption $[8,49]$. The proximal tubule and the distal convoluted tubule, which constitute the majority of tubular segments within the cortex, consume much $\mathrm{O}_{2}$ because a huge amount of osmolytes is resorbed by active transport in these segments. On the other hand, tubular sections such as the thin descending and the thin ascending limbs of Henle's loop and the medullary collecting duct, which are the most abundant tubular sections within the medulla, feature very low to nonexisting active transport. Yet the thick ascending limbs of Henle's loop, which are located in the outer medulla, consume much $\mathrm{O}_{2}$, because of their active resorption of osmolytes $[8,25,41,43-47,50]$. The high $\mathrm{O}_{2}$ demands of the thick ascending limbs in relation to the rather low $\mathrm{O}_{2}$ supply of the outer medulla, consequent to its particular vascular architecture, exposes this renal layer to the greatest risk for hypoxic tissue damage [6-14, 43, 51, 52].

\section{Methods: Methodologic Principles, Advantages, and Disadvantages}

Techniques for invasive measurements of renal hemodynamics and oxygenation comprise readily (commercially) available methods and devices that are employed in many laboratories of integrative kidney physiology worldwide, but also techniques that are established only in one or a few laboratories. The widely used methods are described first. They include (1) perivascular flow probes for measurement of total renal blood flow, (2) laser-Doppler-optodes for assessment of local tissue perfusion, (3) Clark-type electrodes for measurements of local tissue $\mathrm{pO}_{2}$, (4) fluorescence-quenching optodes for the same purpose, (5) devices for invasive measurement of arterial blood pressure, and (6) pimonidazole adduct immunohistochemistry for assessment of renal tissue hypoxia.

The pimonidazole technique is included here because of its widespread usage, although it is an exceptional case for two reasons. First, in contrast to the other techniques, this approach does not allow investigators to monitor a given parameter over time, but 


\subsection{Transonic Flow Probes}

only provides a snapshot: Pimonidazole is injected at a single time point in vivo, and pimonidazole adducts formed in severely hypoxic tissue are visualized in ex vivo samples [53-55]. Second, although the technique has been used for two decades, it was subjected to close scrutiny only recently [55]. Upon this careful investigation major pitfalls were identified and detailed-which, at least in part, cast doubts on the reliability of previously published results-and methods to address and overcome these issues have been proposed [55].

In the final part of this chapter, a few selected examples of methods are discussed that are not (yet) generally available but presently established in only one or a few laboratories.

Today's gold standard for whole kidney blood flow measurements is a flow probe attached to the renal artery or to the renal vein that makes use of ultrasound transit time differences. This method was established in the late 1970s and provides continuous absolute measurements of blood flow (in $\mathrm{mL}$ per min) independent of the actual flow velocity profile, the actual vessel diameter, and the actual hematocrit [56]. The commercially available device (Transonic ${ }^{\mathrm{TM}}$, Transonic Systems Inc.) comprises an electronic flow detection unit (flowmeter) and perivascular probes $[57,58]$. The flow probe consists of two ultrasonic transducers and a fixed acoustic reflector (see Fig. 2a). The flow probe is positioned on the blood vessel so that the vessel lies within the acoustic sensing window defined by

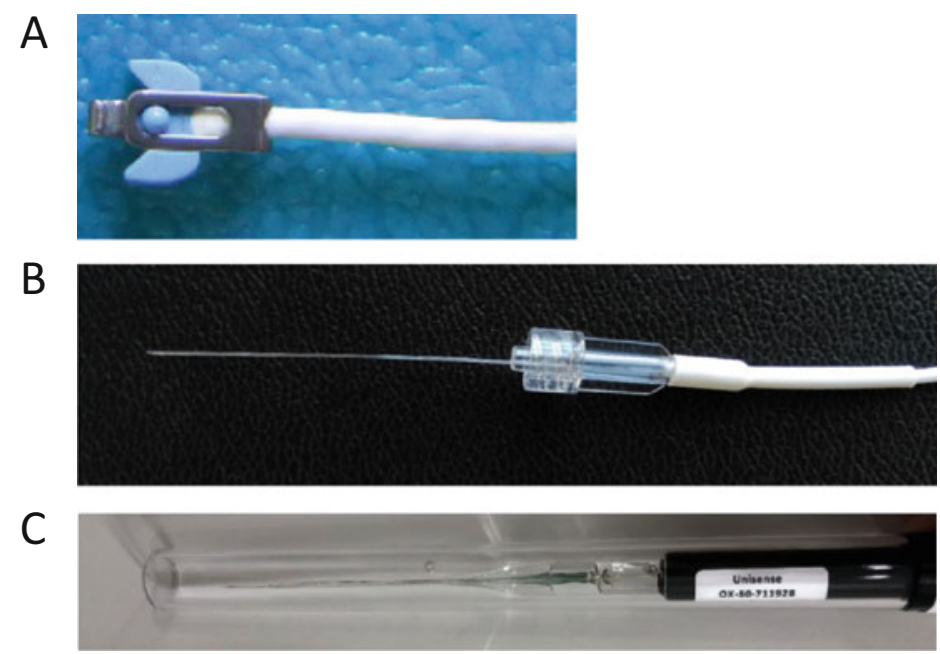

Fig. 2 Photographs of typical probes for invasive measurements. (a) Perivascular Transonic ${ }^{\mathrm{TM}}$ flow probe for measurement of total renal blood flow. (b) Combined fluorescence-quenching-laser-Doppler probe (0xyLite/0xyFlo ${ }^{\mathrm{TM}}$ ) for simultaneous measurements of local tissue $\mathrm{pO}_{2}$ and assessment of local tissue perfusion in the same circumscribed area. (c) Clark-type electrode for measurement of local tissue $\mathrm{pO}_{2}$ 
the transducers and the metallic reflector. Probes are available in various sizes to fit the dimensions of the blood vessel of interest.

The flowmeter directs the flow probe through measurement cycles $[57,58]$. First, a wide beam of ultrasound is emitted by the downstream transducer. It intersects the vessel in the upstream direction, is reflected by the acoustic reflector, then intersects the vessel again before being received by the upstream transducer. The flowmeter records the transit time. Then, the transit-receive sequence is repeated, but with the transmitting and receiving functions of the transducers reversed, that is, the vessel is bisected by the beam in the downstream direction. The transit time during the upstream cycle is higher than during the downstream cycle, because the ultrasound beam travels against the blood flow in the first, and with the blood flow in the latter cycle. The difference in the transit times is directly proportional to blood volume flow. Due to the wide ultrasonic beams, all flowing blood is accounted for; thus, the transit time is sampled at all points across the vessel diameter, and the volume flow measurement is independent of the flow velocity profile $[57,58]$.

An accurate measure of volumetric flow is obtained by the perivascular probes even when the vessel is smaller than the acoustic window, because the parts of the ultrasonic beam that do not intersect the vessel do not contribute to the signal $[57,58]$. However, air effectively blocks ultrasound transmission, and even small air bubbles compromise measurement accuracy. Therefore, all spaces between the vessel and probe must be filled with a suitable acoustic coupling agent. In case of "terminal experiments" in anesthetized animals, where the abdomen is opened, this can be achieved by simply filling the abdominal cavity with isotonic saline (at $37^{\circ} \mathrm{C}$ ) [27]. Acoustic coupling gels can also be used and are available from the supplier of the probes. Fatty tissue also affects the ultrasonic beam; thus, the vessel of interest must be thoroughly prepared by gently removing fatty tissue [27].

Measurements of total renal blood flow by means of Transonic $^{\mathrm{TM}}$ devices have also been performed in chronically instrumented animals [22, 31, 33, 58, 59]. Here, the perivascular probe becomes encapsulated by tissue, which stabilizes its position. En route to calibration of functional MRI for the study of renal hemodynamics and oxygenation, an integrated multimodality approach was developed that enables measurements of invasive gold standard parameters and functional MR parameters simultaneously for the same kidney in an ultrahigh field small animal scanner (MR-PHYSIOL) [25-28]. For such a setup, a special Transonic ${ }^{\mathrm{TM}}$ flow probe is used: its acoustic reflector is made of Macor ceramics instead of stainless steel or brass to meet the safety and compatibility requirements of MRI (see the chapter by Cantow K et al. "Monitoring Renal Hemodynamics and Oxygenation by Invasive Probes: Experimental Protocol”). 


\subsection{Laser-Doppler Optodes}

With the introduction of the Transonic ${ }^{\mathrm{TM}}$ technique, all other methods used for quantitative assessment of total renal blood flow in experimental animals including but not limited to electromagnetic probes and microsphere techniques were rendered obsolete.

In the 1970s, laser-Doppler probes were developed that estimate local blood perfusion within circumscribed areas of tissue $[60,61]$. For this purpose, pulsed light of a distinct wavelength (e.g., $785 \mathrm{~nm}$ ) is guided via an optical fiber into the tissue subjacent to the tip of the fiber, where it is scattered within the tissue. A fraction of the light encounters erythrocytes, is reflected, and is fed back via the fiber to the photodetecting device of the apparatus. From the amount of reflected light the concentration of erythrocytes per tissue volume is estimated. Because erythrocytes move with the bloodstream, the reflected light becomes frequency shifted due to the Doppler effect. The photodetected signal comprises a broad spectrum of Doppler frequency shifted signals from which the average velocity of erythrocytes is derived. An estimate of microvascular blood perfusion is than calculated by the apparatus as the product of mean erythrocyte velocity and mean erythrocyte concentration in the volume of tissue under illumination from the probe [61].

The most important limitation of the laser-Doppler technique is that it can only provide arbitrary, nonabsolute, units for blood perfusion rather than an absolute value of blood flow, which is why the method is often termed laser-Doppler-fluxmetry [25]. This is due to the fact that the actual sampling volume could only be determined if it were possible to identify which erythrocytes have interacted with the light reflected from the tissue. The latter depends on the optical scattering and absorption coefficients of the tissue. Since these coefficients vary considerably with regard to the local microvasculature and its perfusion at the time of measurement, it is impossible to determine the actual sampling volume and thus the blood flow in absolute terms [61].

Estimated mean sampling depths for mammal tissues range from $0.5-1.5 \mathrm{~mm}$, corresponding to "captured" volumes of roughly $\mathrm{l} \mathrm{mm}^{3}$ of tissue. However, these values must be lower in regions with large light absorption due to large amounts of erythrocytes per volume such as the renal cortex, and lower in the inner medulla with its low amount of erythrocytes per volume [38$40,61]$.

Considering the rather small volume of tissue for which the laser-Doppler data are obtained versus the heterogeneity of intrarenal perfusion, extrapolation of the results of one area to other areas, even of the same renal layer, is unfeasible. Because of the impossibility to provide absolute data, laser-Doppler-fluxmetry allows investigators only to report relative changes occurring while the optode is fixed in place. Therefore, only continuous and 


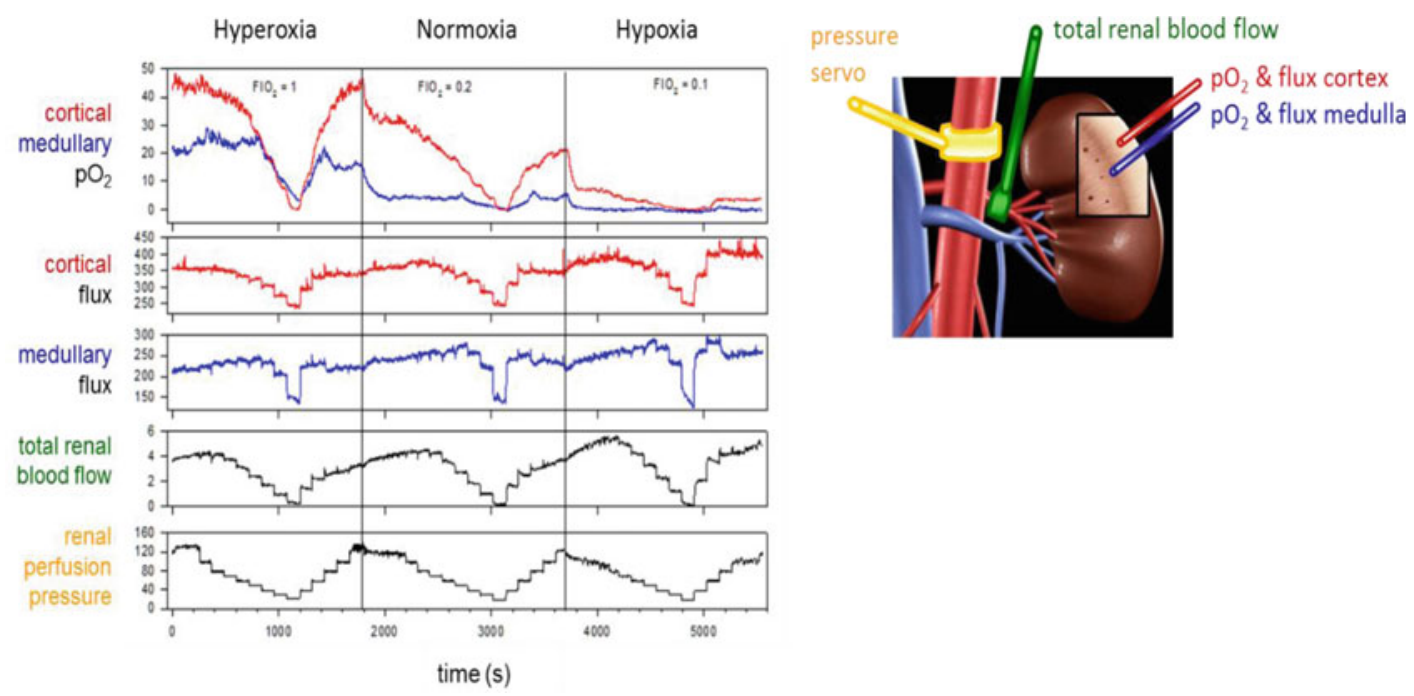

Fig. 3 Original tracings of invasively measured parameters of renal hemodynamic and oxygenation in an anesthetized rat (left panel) and sketch of the left kidney with the locations of the used probes (right panel). The rat was exposed to staircasewise reductions in renal perfusion pressure followed by staircasewise pressure restorations performed by means of a servo-controlled inflatable occluder placed around the suprarenal aorta (pressure servo) [22]. This was done under normoxic (inspiratory fraction of $\mathrm{O}_{2}, \mathrm{FiO}_{2}=0.2$ ), hyperoxic $\left(\mathrm{FiO}_{2}=1.0\right)$, and hypoxic $\left(\mathrm{FiO}_{2}=0.1\right)$ conditions
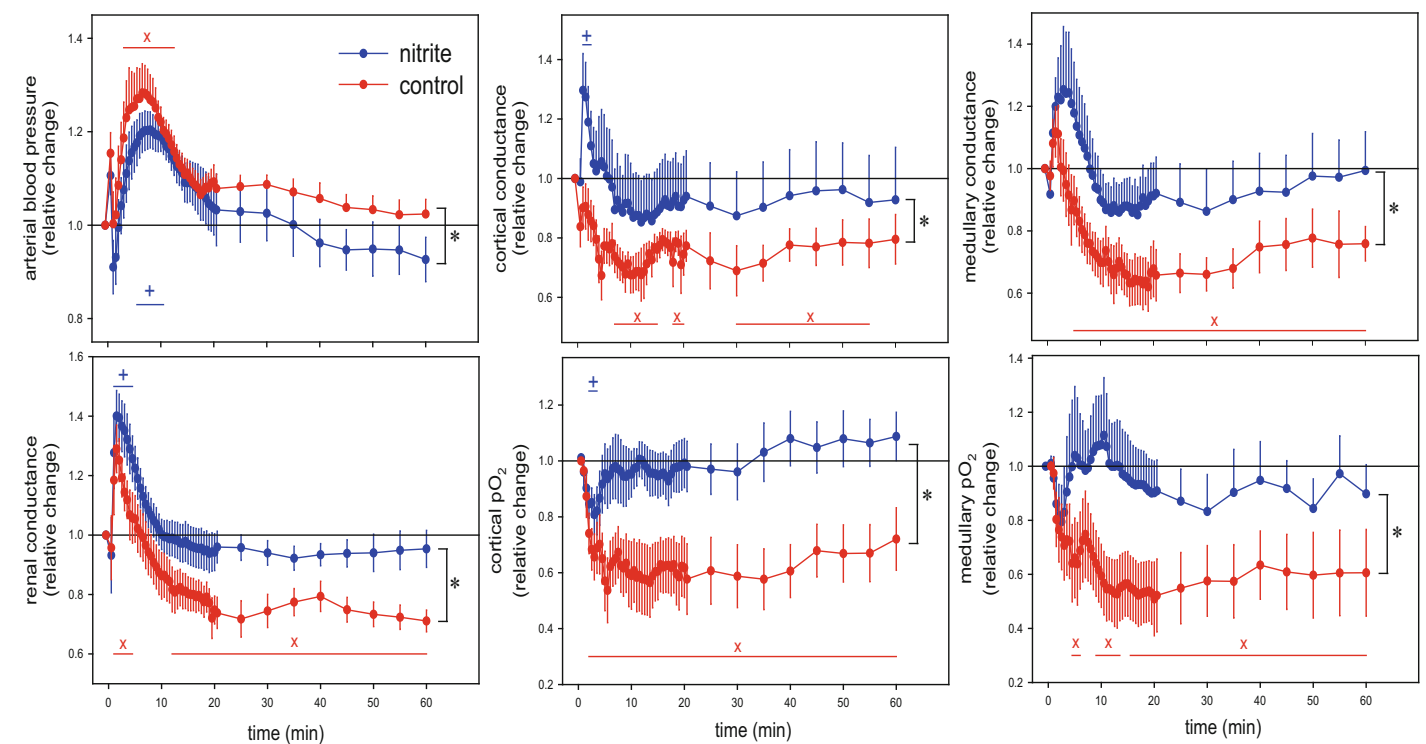

Fig. 4 Time courses of invasively measured parameters of renal hemodynamics and oxygenation in two groups of anesthetized rats that both received a $1.5 \mathrm{~mL}$ bolus injection of an X-ray contrast medium (iodixanol $320 \mathrm{mg}$ iodine per $\mathrm{mL}$ ) into the thoracic aorta at time 0 . In the blue group, a low dose of nitrite was administered by continuous infusion, while in the red group saline was infused (control). Conductance values (the reciprocal of vascular resistance) were calculated by dividing the respective perfusion values by arterial blood pressure, in order to distinguish flow changes that result from passive circular distension/compression of vessels from those actively exerted by vascular smooth muscles. Values (mean $\pm \mathrm{SEM}$ ) are given as relative changes from baseline. Redrawn from Ref. 20 


\subsection{Clark-Type Electrodes}

quantifiable changes relative to baseline (control) measurements are recorded, typically induced by acute interventions such as changes in renal arterial pressure or the inspiratory $\mathrm{O}_{2}$ fraction, or by the administration of drugs (see Figs. 3 and 4) [18-20, 22, 23, $25,28,62]$. Yet even interpretation of changes in laser-Doppler data recorded during such maneuvers must be done with due caution: they could rely on changes in local hematocrit, for example, due to changes in plasma skimming, rather than changes in blood flow $[25,39,48]$.

In many studies on renal hemodynamics, data from two probes are recorded, one placed within the cortex and the other one in the (outer) medulla. This approach has been also employed in chronically instrumented rats [22]. It must be noted, that the potential tissue injury inflicted by the insertion of the optodes (usual tip diameters range from 50 to $300 \mu \mathrm{m}$ ) may confound the results. Laser-Doppler fluxmetry devices are supplied by various manufacturers. Oxford Optronics, Ltd., provides combined fluorescencequenching and laser-Doppler optodes (OxyLite/OxyFlo ${ }^{\text {TM }}$ ) that enable simultaneous recordings of local tissue $\mathrm{pO}_{2}$ (vide infra) and of relative changes in local tissue perfusion in the same circumscribed area of renal tissue (see Fig. 2b).

These polarographic electrodes were developed in the 1950s by Clark and colleagues [63]. The electrodes consist of a noble metal (e.g., silver, gold, platinum) which reduces $\mathrm{O}_{2}$ due to a negative polarizing voltage. The difference in voltage between the reference electrode (anode) and the measuring electrode (cathode) is proportional to the amount of $\mathrm{O}_{2}$ molecules being reduced on the cathode. This enables quantification of tissue $\mathrm{pO}_{2}$ (absolute values in $\mathrm{mmHg}$ ). The critical technical advance was electrical insulation of the anode and cathode with a gas-permeable but liquidimpermeable membrane. This approach provided the foundation for the development of miniaturized versions (see Fig. 2c) with tips as small as $1-5 \mu \mathrm{m}$, that enable quantification of $\mathrm{pO}_{2}$ even in specific vascular and tubular elements of the kidney $[64,65]$. Using such small electrodes, Lübbers, Baumgärtl, and colleagues were the first to document the vast heterogeneity of renal tissue $\mathrm{pO}_{2}$ among as well as within the renal layers that is depicted by Fig. 1 [43-45]. These authors generated "spatial maps" with the frequency distribution of $\mathrm{pO}_{2}$ values ( $\mathrm{pO}_{2}$ histograms") from the cortex to the inner medulla, by moving the electrodes through the renal tissues using a nanostepper technique (step width $50 \mu \mathrm{m}$ ).

While " $\mathrm{pO}_{2}$ histograms" have also been obtained in a few recent studies $[66,67]$, the majority of studies uses fixed electrodes, making sure that the tips remain at the same location within the kidney throughout the experiment. Often, one electrode is placed within the cortex and the other one in the (outer) medulla. The 
tissue volume that is "captured" by the electrodes has probably about the same diameter as the tip of the electrode; thus, standard electrodes of $\leq 10 \mu \mathrm{m}$ diameter obtain $\mathrm{pO}_{2}$ values that are representative for a relatively small tissue volume only [67]. In the face of the spatial heterogeneity of intrarenal $\mathrm{pO}_{2}$, this constitutes a major limitation of this technique. On the other hand, the potential tissue injury inflicted by the insertion of these small electrodes is less than with bigger electrodes or fluorescence quenching optodes that enable better "spatial averaging" (vide infra) [24, 35, 67]. Another drawback of Clark-type electrodes is $\mathrm{O}_{2}$ consumption due to their electrochemical reduction, which is particularly unfavorable in areas with a fragile balance between $\mathrm{O}_{2}$ delivery and demand such as the renal medulla [67-70].

Furthermore, it is not technically feasible to make repeated measurements in the same anesthetized animal over time-frames longer than a few hours. Yet, recently, a telemetric method using carbon paste electrodes has been developed that allows assessment of renal tissue $\mathrm{pO}_{2}$ in conscious rats [35]. This method provides exquisite temporal resolution [24]. The major limitations of the method are (1) that it requires considerable skill and expertise to construct and implant the devices, $(2)$ that tissue $\mathrm{pO}_{2}$ can only be monitored at a single location in each animal, and (3) that only relative changes in tissue $\mathrm{pO}_{2}$, rather than absolute levels are measured.

3.4 FluorescenceQuenching Optodes
In the 1990s, a fiber-optic oxygen-sensing device was developed that measures $\mathrm{pO}_{2}$ from the lifetime of fluorescence of a (ruthenium- or platinum-based) luminophore at the tip of an optode $[70,71]$. The probe is connected to a $\mathrm{pO}_{2}$ meter developed by Oxford Optronics, Ltd., that generates short pulses of blue LED light, which are transmitted via the fiber to the tip of the optode [70]. The resulting emission of fluorescent light is quenched by the presence of $\mathrm{O}_{2}$ molecules. The OxyLite ${ }^{\mathrm{TM}}$ instrument measures the lifetime of each pulse of fluorescence, which is approximately inversely proportional to the $\mathrm{pO}_{2}$ according to the Stern-Volmer equation at $\mathrm{pO}_{2}$ values between 0 and $100 \mathrm{mmHg}[68,7 \mathrm{l}]$.

Direct comparisons between Clark-type electrodes and quenching optodes reveal their respective advantages and disadvantages $[67,68,70]$. Both techniques share the disadvantage of invasiveness, and the advantage of enabling absolute quantification of $\mathrm{pO}_{2}$ (in $\mathrm{mmHg}$ ). Advantages of the optode include the absence of $\mathrm{O}_{2}$ consumption and a greater accuracy at low $\mathrm{pO}_{2}$, which is of particular importance when it comes to measurements in the renal medulla. In contrast to the electrodes that "capture" a tissue volume that is approximately equal to their tip diameter, optodes do not "capture" a proper volume. The $\mathrm{pO}_{2}$ measured by the optodes is that within the probe-head (at the tip) of the optode itself, which covers a circular area of $230 \mu \mathrm{m}$ diameter $[67,68,70]$. The larger 


\subsection{Monitoring of Arterial Blood Pressure}

3.6 Pimonidazole Adduct Immunohistochemistry diameter of the optodes as compared with that of standard $\mathrm{pO}_{2}$ electrodes increases the risk for tissue damage. On the other hand, it facilitates a favorable "spatial averaging" of renal tissue $\mathrm{pO}_{2}$ values in the face of their huge spatial heterogeneity. In fact, " $\mathrm{pO}_{2}$ histograms" of renal cortical $\mathrm{pO}_{2}$ obtained in rabbits by a fluorescence optode were more tightly distributed than those provided by a Clark-type electrode, which may aid detection of (patho)physiologically significant changes in intrarenal oxygenation [67]. Finally, the optodes have been proven to be MR compatible and MR safe $[25,26]$.

As mentioned earlier, combined fluorescence-quenching-laserDoppler probes (OxyLite/OxyFlo ${ }^{\mathrm{TM}}$ ) enable simultaneous measurements of local tissue $\mathrm{pO}_{2}$ and assessment of local tissue perfusion in the same circumscribed area (see Fig. 2b).

It is mandatory for in vivo studies in anesthetized experimental animals, be it studies on control of renal hemodynamics and oxygenation or on every other functional parameter, to monitor cardiovascular variables such as arterial blood pressure and heart rate throughout the experiment in order to ascertain that physiological cardiovascular control is maintained. In anesthetized animals this is best achieved by use of invasive techniques: a fluid-filled catheter inserted into a conduit artery (e.g., femoral or carotid arteries) connected to one of the various commercially available pressure transducers and quantitatively calibrated via a recording device (see the chapter by Cantow Ket al. "Monitoring Renal Hemodynamics and Oxygenation by Invasive Probes: Experimental Protocol”).

Direct intra-arterial measurements in unanesthetized animals is the most physiologically relevant means of arterial pressure determination. Telemetric pressure monitoring is the gold standard in conscious animals, and various telemetric devices are commercially available $[72,73]$. A limitation of this technique is that implantation surgery and maintenance of catheters require considerable skill [72]. The tail-cuff method is a simple noninvasive plethysmographic technique to assess arterial pressure in conscious rats and mice $[74,75]$. Since the conditions for tail-cuff measurements necessarily involve heating and restraint of the animal, which almost inevitably alter the measured parameter (arterial pressure), the physiological meaningfulness of the results is questionable [73].

This method was originally developed for detection of hypoxia in tumors, but subsequently adapted for use in the kidney [53]. For this technique, pimonidazole (usually $60 \mathrm{mg} / \mathrm{kg}$ of body mass) is administered to the experimental animal in vivo [54]. Pimonidazole forms adducts within hypoxic (<approximately $10 \mathrm{mmHg}$ ) cells. These adducts are immunohistochemically visualized in ex vivo samples of the kidney. The advantage of this technique is that it provides good spatial resolution of renal tissue hypoxia at the 


\subsection{Examples of Methods That Are Not Generally Available}

3.7.1 Bladder $\mathrm{pO}_{2}$

3.7.2 Near Infrared Spectroscopy cellular level. Its major limitations include (1) that it detects severe hypoxia only, with a cutoff of about $10 \mathrm{mmHg},(2)$ that hypoxia can only be assessed postmortem, and (3) only at a single time point. Those using this technique must also be aware of two major sources of false-positive detection of hypoxia, as recently revealed [55]. Firstly, pimonidazole adducts can form postmortem in cells that were not hypoxic in the living animal. For this reason, it is recommended that kidney tissue be perfusion fixed, rather than immersion fixed. Secondly, when the standard (mouse) monoclonal antibody is used, false positive staining has been observed in damaged rat kidney tissue, presumably as a result of the anti-mouse secondary antibody binding to mouse-like antigens in the damaged tissue. This problem can be avoided by use of a newly commercially available polyclonal anti-pimonidazole antibody raised in rabbits [55].

It is not technically feasible to measure renal tissue $\mathrm{pO}_{2}$ in humans. It can also be technically difficult to measure renal tissue $\mathrm{pO}_{2}$ in experimental animals unless they are deeply anesthetized. However, it is technically feasible to measure the $\mathrm{pO}_{2}$ of urine in both experimental animals and man. There has been a long history of interest in this approach for monitoring renal medullary tissue oxygenation [76]. However, with the recent development of fiber-optic probes that can be inserted into a standard Foley bladder catheter, it has been possible to subject this method to close scrutiny [77]. Available evidence now indicates that urinary $\mathrm{pO}_{2}$ can provide a good estimate of renal medullary $\mathrm{pO}_{2}$ [77]. Because this technique can be deployed in humans equipped with a bladder catheter, it provides a translational pathway for development of approaches to improve renal medullary oxygenation in human patients at risk of AKI. It is also noteworthy that low urinary $\mathrm{pO}_{2}$ during cardiac surgery requiring cardiopulmonary bypass predicts development of postoperative AKI. In light of this, urinary $\mathrm{pO}_{2}$ measurements may provide a real-time measure of medullary oxygenation and predict the risk of AKI in critically ill patients. The major limitation of this approach is that the combination of low urine flow and high arterial $\mathrm{pO}_{2}$ can confound the relationship between urinary $\mathrm{pO}_{2}$ and medullary $\mathrm{pO}_{2}$ [77].

Near infrared spectroscopy (NIRS), together with models for diffuse optical imaging affords the measurement of (1) tissue concentrations of oxygenated hemoglobin $(\mathrm{oxyHb})$ and deoxygenated hemoglobin (deoxyHb), (2) oxygen saturation of $\mathrm{Hb}\left(\mathrm{StO}_{2}\right)$ within tissues, and (3) tissue blood volume fraction in vivo. In particular, spatially resolved reflectance NIRS (SRR-NIRS), together with Monte-Carlo simulations of diffuse light propagation, has been applied to monitor these parameters within renal 
cortical tissue [78]. Quantification of the underlying absorption and reduced scattering coefficients of the tissue is based on analyzing the decrease of the intensity of diffusely remitted light with increasing distance from the light injection point. Recording techniques for the renal cortex of anesthetized rats have been established, with a linear fiber array placed on the ventral surface of the exposed kidney. Measurements have been done at selected nearinfrared wavelengths between about 670 and $850 \mathrm{~nm}$ by multiplexing millisecond pulses from the different laser sources in time. In this way, quantitative measurements of renal cortex parameters have been achieved at a repetition rate of multiple $\mathrm{Hz}$ [78].

SRR-NIRS has been successfully combined with "classical" invasive techniques to study renal hemodynamics and oxygenation in rats [78]. Thus, SRR-NIRS-derived parameters such as the amount of $\mathrm{Hb}$ per tissue volume and $\mathrm{StO}_{2}$ were obtained simultaneously with parameters including total renal blood flow, local cortical tissue perfusion and tissue $\mathrm{pO}_{2}$ in the same kidney. Control of renal hemodynamics and oxygenation was studied by dedicated reversible test interventions including brief occlusions of the renal artery or the renal vein, short-term hypoxia, hyperoxia, and hypercapnia, and administration of adenosine. The results demonstrate that the combined approach, by providing different but complementary information, enables a more comprehensive characterization of renal hemodynamics and oxygenation [78].

The SRR-NIRS technique could also serve to help calibrate renal $\mathrm{T}_{2}$ * MRI. This MR surrogate parameter for blood oxygenation is related to the amount of deoxyHb per tissue volume. Confounders of the $\mathrm{T}_{2}$ * to tissue $\mathrm{pO}_{2}$ relationship include the vascular volume fraction, the local hematocrit, and shifts of the oxyHb dissociation curve [25-28]. Since SRR-NIRS enables quantitative monitoring of the amount of $\mathrm{Hb}$ per tissue volume and of $\mathrm{StO}_{2}$ it is an ideal candidate to unravel and quantify the contributions of confounding factors to renal $\mathrm{T}_{2}$ * MRI.

By extending the wavelength range beyond $900 \mathrm{~nm}$, the tissue water content can additionally be assessed, which, together with the reduced scattering coefficients at the different wavelengths, can serve as a surrogate for other (patho)physiologically relevant parameters such as the tubular volume fraction.

Application of SRR-NIRS in reflection mode constrains measurements to the renal cortex of rats. Recently it was demonstrated that changes of rat medullary $\mathrm{Hb}$ parameters can also be assessed by SRR-NIRS in transmission mode using an additional fiber placed on the dorsal surface of the kidney [79].

3.7.3 Intravital Microscopy
Perhaps the "final frontier" in methods for assessing renal oxygenation are techniques that provide cellular resolution, in real time, in living animals. Hirakawa and colleagues have recently reported use 
of a technique they call "intravital phosphorescence lifetime imaging microscopy" [47]. This technique allows cellular $\mathrm{pO}_{2}$ in the renal cortex of live animals to be resolved to the level of individual tubular cross-sections. It requires injection of a molecule whose phosphorescence is quenched by $\mathrm{O}_{2}$. Thus, $\mathrm{pO}_{2}$ can be measured by assessing the decay curve of the phosphorescence. Such probes are available that accumulate intracellularly or are retained within the vasculature. Thus, it is possible to use this approach to assess the heterogeneity of renal blood and tissue $\mathrm{pO}_{2}$ in real time with unprecedented cellular resolution. Currently, the technique is limited for use in the superficial cortex.

\section{Acknowledgments}

This work was funded, in part (Kathleen Cantow, Thoralf Niendorf, and Erdmann Seeliger), by the German Research Foundation (Gefoerdert durch die Deutsche Forschungsgemeinschaft (DFG), Projektnummer/Project number 394046635, SFB 1365, RENOPROTECTION).

The authors wish to thank Ariane Anger and Andrea Gerhardt for expert technical assistance and Dr. Connie Ow for the image shown in Fig. 2c.

This chapter is based upon work from COST Action PARENCH IMA, supported by European Cooperation in Science and Technology (COST). COST (www.cost.eu) is a funding agency for research and innovation networks. COST Actions help connect research initiatives across Europe and enable scientists to enrich their ideas by sharing them with their peers. This boosts their research, career, and innovation.

PARENCHIMA (renalmri.org) is a community-driven Action in the COST program of the European Union, which unites more than 200 experts in renal MRI from 30 countries with the aim to improve the reproducibility and standardization of renal MRI biomarkers.

\section{References}

1. Fortrie G, de Geus HRH, Betjes MGH (2019) The aftermath of acute kidney injury: a narrative review of long-term mortality and renal function. Crit Care 23(1):24. https://doi. org/10.1186/s13054-019-2314-z

2. Selby NM, Taal MW (2019) Long-term outcomes after AKI-a major unmet clinical need. Kidney Int 95(1):21-23. https://doi.org/10. 1016/j.kint.2018.09.005

3. Zuk A, Bonventre JV (2019) Recent advances in acute kidney injury and its consequences and impact on chronic kidney disease. Curr Opin
Nephrol Hypertens 28(4):397-405. https:// doi.org/10.1097/mnh.0000000000000504

4. Levin A, Tonelli M, Bonventre J, Coresh J, Donner JA, Fogo AB, Fox CS, Gansevoort RT, Heerspink HJL, Jardine M, Kasiske B, Kottgen A, Kretzler M, Levey AS, Luyckx VA, Mehta R, Moe O, Obrador G, Pannu N, Parikh CR, Perkovic V, Pollock C, Stenvinkel P, Tuttle KR, Wheeler DC, Eckardt KU (2017) Global kidney health 2017 and beyond: a roadmap for closing gaps in care, research, and policy. Lancet 390(10105):1888-1917. https://doi.org/ $10.1016 / \mathrm{s} 0140-6736(17) 30788-2$ 
5. Bello AK, Levin A, Tonelli M, Okpechi IG, Feehally J, Harris D, Jindal K, Salako BL, Rateb A, Osman MA, Qarni B, Saad S, Lunney $M$, Wiebe $\mathrm{N}$, Ye F, Johnson DW (2017) Assessment of global kidney health care status. JAMA 317(18):1864-1881. https://doi.org/10.1001/jama.2017.4046

6. Brezis M, Rosen S (1995) Hypoxia of the renal medulla--its implications for disease. N Engl J Med 332:647-655

7. Fähling M, Seeliger E, Patzak A, Persson PB (2017) Understanding and preventing contrast-induced acute kidney injury. Nat Rev Nephrol 13(3):169-180

8. Evans RG, Ince C, Joles JA, Smith DW, May CN, O'Connor PM, Gardiner BS (2013) Haemodynamic influences on kidney oxygenation: the clinical implications of integrative physiology. Clin Exp Pharmacol Physiol 40:106-122

9. Evans RG, Ow CP, Bie P (2015) The chronic hypoxia hypothesis: the search for the smoking gun goes on. Am J Physiol Renal Physiol 308 (2):F101-F102

10. Shu S, Wang Y, Zheng M, Liu Z, Cai J, Tang C, Dong Z (2019) Hypoxia and hypoxiainducible factors in kidney injury and repair. Cell 8(3). https://doi.org/10.3390/ cells 8030207

11. Hultstrom M, Becirovic-Agic M, Jonsson S (2018) Comparison of acute kidney injury of different etiology reveals in-common mechanisms of tissue damage. Physiol Genomics 50 (3):127-141. https://doi.org/10.1152/ physiolgenomics.00037.2017

12. Calzavacca P, Evans RG, Bailey M, Bellomo R, May CN (2015) Cortical and medullary tissue perfusion and oxygenation in experimental septic acute kidney injury. Crit Care Med 43 (10):e431-e439

13. Ma S, Evans RG, Iguchi N, Tare M, Parkington HC, Bellomo R, May CN, Lankadeva YR (2019) Sepsis-induced acute kidney injury: a disease of the microcirculation. Microcirculation 26(2):e12483. https://doi.org/10. $1111 /$ micc. 12483

14. dos Santos EA, Li LP, Ji L, Prasad PV (2007) Early changes with diabetes in renal medullary hemodynamics as evaluated by fiberoptic probes and BOLD magnetic resonance imaging. Investig Radiol 42(3):157-162. https:// doi.org/10.1097/01.rli.0000252492. 96709.36

15. Calvin AD, Misra S, Pflueger A (2010) Contrast-induced acute kidney injury and diabetic nephropathy. Nat Rev Nephrol 6 (11):679-688
16. Hansell P, Welch WJ, Blantz RC, Palm F (2013) Determinants of kidney oxygen consumption and their relationship to tissue oxygen tension in diabetes and hypertension. Clin Exp Pharmacol Physiol 40(2):123-137

17. Seeliger E, Flemming B, Wronski T, Ladwig M, Arakelyan K, Godes M, Mockel M, Persson PB (2007) Viscosity of contrast media perturbs renal hemodynamics. J Am Soc Nephrol 18 (11):2912-2920

18. Hoff U, Lukitsch I, Chaykovska L, Ladwig M, Arnold C, Manthati VL, Fuller TF, Schneider W, Gollasch M, Muller DN, Flemming B, Seeliger E, Luft FC, Falck JR, Dragun D, Schunck WH (2011) Inhibition of 20-HETE synthesis and action protects the kidney from ischemia/reperfusion injury. Kidney Int 79(1):57-65

19. Cantow K, Flemming B, Ladwig-Wiegard M, Persson PB, Seeliger E (2017) Low dose nitrite improves reoxygenation following renal ischemia in rats. Sci Rep 7(1):14597-15058

20. Seeliger E, Cantow K, Arakelyan K, Ladwig M, Persson PB, Flemming B (2014) Low-dose nitrite alleviates early effects of an X-ray contrast medium on renal hemodynamics and oxygenation in rats. Investig Radiol 49(2):70-77

21. Seeliger E, Wronski T, Ladwig M, Dobrowolski L, Vogel T, Godes M, Persson PB, Flemming B (2009) The renin-angiotensin system and the third mechanism of renal blood flow autoregulation. Am J Physiol Renal Physiol 296(6):F1334-F1345

22. Flemming B, Seeliger E, Wronski T, Steer K, Arenz N, Persson PB (2000) Oxygen and renal hemodynamics in the conscious rat. J Am Soc Nephrol 11(1):18-24

23. Cantow K, Pohlmann A, Flemming B, Ferrara F, Waiczies S, Grosenick D, Niendorf T, Seeliger E (2016) Acute effects of ferumoxytol on regulation of renal hemodynamics and oxygenation. Sci Rep 6:29965. https://doi.org/10.1038/srep29965

24. Emans TW, Janssen BJ, Pinkham MI, Ow CP, Evans RG, Joles JA, Malpas SC, Krediet CT, Koeners MP (2016) Exogenous and endogenous angiotensin-II decrease renal cortical oxygen tension in conscious rats by limiting renal blood flow. J Physiol 594(21):6287-6300. https://doi.org/10.1113/jp270731

25. Pohlmann A, Cantow K, Hentschel J, Arakelyan K, Ladwig M, Flemming B, Hoff U, Persson PB, Seeliger E, Niendorf T (2013) Linking non-invasive parametric MRI with invasive physiological measurements (MR-PHYSIOL): towards a hybrid and integrated approach for investigation of acute 
kidney injury in rats. Acta Physiol (Oxf) 207 (4):673-689

26. Niendorf T, Pohlmann A, Arakelyan K, Flemming B, Cantow K, Hentschel J, Grosenick D, Ladwig M, Reimann H, Klix S, Waiczies S, Seeliger E (2015) How BOLD is blood oxygenation level-dependent (BOLD) magnetic resonance imaging of the kidney? Opportunities, challenges and future directions. Acta Physiol (Oxf) 213(1):19-38

27. Cantow K, Arakelyan K, Seeliger E, Niendorf T, Pohlmann A (2016) Assessment of renal hemodynamics and oxygenation by simultaneous magnetic resonance imaging (MRI) and quantitative invasive physiological measurements. Methods Mol Biol 1397:129-154. https://doi.org/10.1007/ 978-1-4939-3353-2_11

28. Pohlmann A, Arakelyan K, Hentschel J, Cantow K, Flemming B, Ladwig M, Waiczies S, Seeliger E, Niendorf T (2014) Detailing the relation between renal $\mathrm{T}_{2}$ * and renal tissue $\mathrm{pO}_{2}$ using an integrated approach of parametric magnetic resonance imaging and invasive physiological measurements. Investig Radiol 49(8):547-560

29. Evans RG, Gardiner BS, Smith DW, O'Connor PM (2008) Methods for studying the physiology of kidney oxygenation. Clin Exp Pharmacol Physiol 35(12):1405-1412

30. Hirakawa Y, Tanaka T, Nangaku M (2017) Renal hypoxia in CKD; pathophysiology and detecting methods. Front Physiol 8:99. https://doi.org/10.3389/fphys.2017.00099

31. Flemming B, Arenz N, Seeliger E, Wronski T, Steer K, Persson PB (2001) Time-dependent autoregulation of renal blood flow in conscious rats. J Am Soc Nephrol 12(11):2253-2262

32. Calzavacca P, Evans RG, Bailey M, Bellomo R, May CN (2015) Variable responses of regional renal oxygenation and perfusion to vasoactive agents in awake sheep. Am J Physiol Regul Integr Comp Physiol 309(10):R1226-R1233

33. Calzavacca P, Evans RG, Bailey M, Lankadeva YR, Bellomo R, May CN (2015) Long-term measurement of renal cortical and medullary tissue oxygenation and perfusion in unanesthetized sheep. Am J Physiol Regul Integr Comp Physiol 308(10):R832-R839

34. Evans RG, Madden AC, Denton KM (2000) Diversity of responses of renal cortical and medullary blood flow to vasoconstrictors in conscious rabbits. Acta Physiol Scand 169 (4):297-308

35. Koeners MP, Ow CP, Russell DM, Abdelkader A, Eppel GA, Ludbrook J, Malpas SC, Evans RG (2013) Telemetry-based oxygen sensor for continuous monitoring of kidney oxygenation in conscious rats. Am J Physiol Renal Physiol 304(12):Fl471-F1480

36. Koeners MP, Ow CPC, Russell DM, Evans RG, Malpas SC (2016) Prolonged and continuous measurement of kidney oxygenation in conscious rats. Methods Mol Biol 1397:93-111. https://doi.org/10.1007/978-1-4939-33532_9.:93-111

37. Lankadeva YR, Kosaka J, Evans RG, Bailey SR, Bellomo R, May CN (2016) Intrarenal and urinary oxygenation during norepinephrine resuscitation in ovine septic acute kidney injury. Kidney Int 90(1):100-108

38. Pitts RF (1974) Anatomy of the kidney. In: Pitts RF (ed) Physiology of the kidney and body fluids. Year Book Medical Publishers, Inc., Chicago

39. Edwards A, Silldforff EP, Pallone TL (2000) The renal medullary microcirculation. Front Biosci 5:E36-E52

40. Zimmerhackl BL, Robertson CR, Jamison RL (1987) The medullary microcirculation. Kidney Int 31(2):641-647

41. Evans RG, Gardiner BS, Smith DW, O'Connor PM (2008) Intrarenal oxygenation: unique challenges and the biophysical basis of homeostasis. Am J Physiol Renal Physiol 295 (5):1259-1270

42. Niendorf T, Pohlmann A, Arakelyan K, Flemming $\mathrm{B}$, Cantow $\mathrm{K}$, Hentschel J, Grosenick D, Ladwig M, Reimann H, Klix S, Waiczies S, Seeliger E (2015) How BOLD is blood oxygenation-dependent (BOLD) magnetic resonance imaging of the kidney? Opportunities, challenges and future directions. Acta Physiol (Oxf) 213(1):19-38

43. Schurek HJ (1988) Kidney medullary hypoxia: a key to understanding acute renal failure? Klin Wochenschr 66(18):828-835

44. Baumgartl H, Leichtweiss HP, Lubbers DW, Weiss C, Huland H (1972) The oxygen supply of the dog kidney: measurements of intrarenal $\mathrm{pO}_{2}$. Microvasc Res 4(3):247-257

45. Lubbers DW, Baumgartl H (1997) Heterogeneities and profiles of oxygen pressure in brain and kidney as examples of the $\mathrm{pO}_{2}$ distribution in the living tissue. Kidney Int 51(2):372-380

46. Evans RG, Ow CPC (2018) Heterogeneity of renal cortical oxygenation: seeing is believing. Kidney Int 93(6):1278-1280. https://doi. org/10.1016/j.kint.2018.01.039

47. Hirakawa Y, Mizukami K, Yoshihara T, Takahashi I, Khulan P, Honda T, Mimura I, Tanaka T, Tobita S, Nangaku M (2018) Intravital phosphorescence lifetime imaging of the renal cortex accurately measures renal hypoxia. 
Kidney Int 93(6):1483-1489. https://doi. org/10.1016/j.kint.2018.01.015

48. Pappenheimer JR, Kinter WB (1956) Hematocrit ratio of blood within mammalian kidney and its significance for renal hemodynamics. Am J Physiol 185:377

49. Evans RG, Harrop GK, Ngo JP, Ow CP, O'Connor PM (2014) Basal renal $\mathrm{O}_{2}$ consumption and the efficiency of $\mathrm{O}_{2}$ utilization for $\mathrm{Na}^{+}$reabsorption. Am J Physiol Renal Physiol 306(5):F551-F560

50. Pitts RF (1974) Mechanisms of reabsorption and excretion of salt and water. In: Pitts RF (ed) Physiology of the kidney and body fluids. Year Book Medical Publishers, Inc., Chicago

51. Palm F, Carlsson PO, Hansell P, Hellberg O, Nygren A, Liss P (2003) Altered response in renal blood flow and oxygen tension to contrast media in diabetic rats. Acta Radiol 44 (3):347-353

52. Palm F, Cederberg J, Hansell P, Liss P, Carlsson PO (2003) Reactive oxygen species cause diabetes-induced decrease in renal oxygen tension. Diabetologia 46(8):1153-1160

53. Zhong Z, Arteel GE, Connor HD, Yin M, Frankenberg MV, Stachlewitz RF, Raleigh JA, Mason RP, Thurman RG (1998) Cyclosporin a increases hypoxia and free radical production in rat kidneys: prevention by dietary glycine. Am J Physiol 275(4):F595-F604. https://doi.org/ 10.1152/ajprenal.1998.275.4.F595

54. Rosenberger C, Rosen S, Paliege A, Heyman SN (2009) Pimonidazole adduct immunohistochemistry in the rat kidney: detection of tissue hypoxia. Methods Mol Biol 466:161-174. https://doi.org/10.1007/978-1-59745-3523_12

55. Ow CPC, Ullah MM, Ngo JP, Sayakkarage A, Evans RG (2019) Detection of cellular hypoxia by pimonidazole adduct immunohistochemistry in kidney disease: methodological pitfalls and their solution. Am J Physiol Renal Physiol 317(2):F322. https://doi.org/10.1152/ ajprenal.00219.2019

56. Drost CJ (1978) Vessel diameter-independent volume flow measurements using ultrasound. In: Proceedings of San Diego Biomedical Symposium, vol 17. San Diego Biomedical Society, San Diego, CA, pp 299-302

57. Dean DA, Jia CX, Cabreriza SE, D’Alessandro DA, Dickstein ML, Sardo MJ, Chalik N, Spotnitz HM (1996) Validation study of a new transit time ultrasonic flow probe for continuous great vessel measurements. ASAIO J 42(5): M671-M676

58. Charbel FT, Hoffman WE, Misra M, Ostergren L (1998) Ultrasonic perivascular flow probe: technique and application in neurosurgery. Neurol Res 20(5):439-442

59. Lankadeva YR, Cochrane AD, Marino B, Iguchi N, Hood SG, Bellomo R, May CN, Evans RG (2019) Strategies that improve renal medullary oxygenation during experimental cardiopulmonary bypass may mitigate postoperative acute kidney injury. Kidney Int 95(6):1338-1346. https://doi.org/10.1016/ j.kint.2019.01.032

60. Stern MD, Bowen PD, Parma R, Osgood RW, Bowman RL, Stein JH (1979) Measurement of renal cortical and medullary blood flow by laser-Doppler spectroscopy in the rat. Am J Physiol 236(1):F80-F87. https://doi.org/10. 1152/ajprenal.1979.236.1.F80

61. Obeid AN, Barnett NJ, Dougherty G, Ward G (1990) A critical review of laser Doppler flowmetry. J Med Eng Technol 14(5):178-181

62. Ferrara F, Cantow K, Flemming B, Skalweit A, Ladwig M, Fähling M, Seeliger E (2017) Effects of liraglutide on control of renal hemodynamics and oxygenation in diabetic rats. Acta Physiol (Oxf) 219(Suppl. 711):38

63. Clark LC Jr, Misrahy G, Fox RP (1958) Chronically implanted polarographic electrodes. J Appl Physiol 13(1):85-91. https://doi. org/10.1152/jappl.1958.13.1.85

64. Whalen WJ, Riley J, Nair P (1967) A microelectrode for measuring intracellular PO2. J Appl Physiol 23(5):798-801. https://doi. org/10.1152/jappl.1967.23.5.798

65. Welch WJ, Baumgartl H, Lubbers D, Wilcox CS (2001) Nephron $\mathrm{pO}_{2}$ and renal oxygen usage in the hypertensive rat kidney. Kidney Int $59(1): 230-237$. https://doi.org/10. 1046/j.1523-1755.2001.00483.x

66. Ow CPC, Ngo JP, Ullah MM, Barsha G, Meex RC, Watt MJ, Hilliard LM, Koeners MP, Evans RG (2018) Absence of renal hypoxia in the subacute phase of severe renal ischemiareperfusion injury. Am J Physiol Renal Physiol 315(5):F1358-f1369. https://doi.org/10. 1152 /ajprenal.00249.2018

67. Leong CL, O'Connor PM, Eppel GA, Anderson WP, Evans RG (2008) Measurement of renal tissue oxygen tension: systematic differences between fluorescence optode and microelectrode recordings in anaesthetized rabbits. Nephron Physiol 108(2):11-17

68. Shaw AD, Li Z, Thomas Z, Stevens CW (2002) Assessment of tissue oxygen tension: comparison of dynamic fluorescence quenching and polarographic electrode technique. Crit Care 6(1):76-80

69. Carreau A, El Hafny-Rahbi B, Matejuk A, Grillon C, Kieda C (2011) Why is the partial 
oxygen pressure of human tissues a crucial parameter? Small molecules and hypoxia. J Cell Mol Med 15(6):1239-1253. https://doi. org/10.1111/j.1582-4934.2011.01258.x

70. Griffiths JR, Robinson SP (1999) The OxyLite: a fibre-optic oxygen sensor. Br J Radiol 72 (859):627-630. https://doi.org/10.1259/ bjr.72.859.10624317

71. Young WK, Vojnovic B, Wardman P (1996) Measurement of oxygen tension in tumours by time-resolved fluorescence. British J Cancer Suppl 27:S256-S259

72. Sponer G, Müller-Beckmann B, Martin U (1993) Blood pressure recording in rats: pitfalls and problems. In: Gretz N, Strauch M (eds) Experimental and genetic rat models of chronic renal failure. Karger, Basel, pp 319-330

73. Nalivaiko E (2011) Animal models of psychogenic cardiovascular disorders: what we can learn from them and what we cannot. Clin Exp Pharmacol Physiol 38(2):115-125. https://doi.org/10.1111/j.1440-1681.2010. 05465.x

74. Byrom FB, Wilson C (1938) A plethysmographic method for measuring systolic blood pressure in the intact rat. J Physiol 93 (3):301-304. https://doi.org/10.1113/ jphysiol.1938.sp003641
75. Krege JH, Hodgin JB, Hagaman JR, Smithies $\mathrm{O}$ (1995) A noninvasive computerized tail-cuff system for measuring blood pressure in mice. Hypertension 25(5):1111-1115. https://doi. org/10.1161/01.hyp.25.5.1111

76. Aperia AC, Liebow AA (1964) Implications of urinary pO2 for renal medullary blood flow. Am J Physiol 206:499-504

77. Ngo JP, Lankadeva YR, Zhu MZL, Martin A, Kanki M, Cochrane AD, Smith JA, Thrift AG, May CN, Evans RG (2019) Factors that confound the prediction of renal medullary oxygenation and risk of acute kidney injury from measurement of bladder urine oxygen tension. Acta Physiol (Oxf) 227(1):el3294. https:// doi.org/10.1111/apha.13294

78. Grosenick D, Cantow K, Arakelyan K, Wabnitz H, Flemming B, Skalweit A, Ladwig M, Macdonald R, Niendorf T, Seeliger E (2015) Detailing renal hemodynamics and oxygenation in rats by a combined nearinfrared spectroscopy and invasive probe approach. Biomed Opt Express 6(2):309-323

79. Gladytz T, Cantow K, Flemming B, Pohlmann A, Niendorf T, Seeliger E, Grosenick D Towards depth-resolved characterization of hemodynamics and oxygenation in the rat kidney. In Proc SPIE, 2019. vol 11074, pp 1107415-1107411-1107415-1107413

Open Access This chapter is licensed under the terms of the Creative Commons Attribution 4.0 International License (http://creativecommons.org/licenses/by/4.0/), which permits use, sharing, adaptation, distribution and reproduction in any medium or format, as long as you give appropriate credit to the original author(s) and the source, provide a link to the Creative Commons license and indicate if changes were made.

The images or other third party material in this chapter are included in the chapter's Creative Commons license, unless indicated otherwise in a credit line to the material. If material is not included in the chapter's Creative Commons license and your intended use is not permitted by statutory regulation or exceeds the permitted use, you will need to obtain permission directly from the copyright holder. 